\section{IS YOUR RETIREMENT OF HIGH PRIORITY?}

There is so much happening at the moment regarding pensions; the new 2015 NHS pension scheme, the proposed reduction in the lifetime allowance as well as the introduction of flexible pensions.

How is your future looking? The new NHS pension scheme has been encouraging dentists to look at their entire retirement plan to ensure they won't fall short at that important time in life when relaxation is high priority.

Will the NHS pension provide you

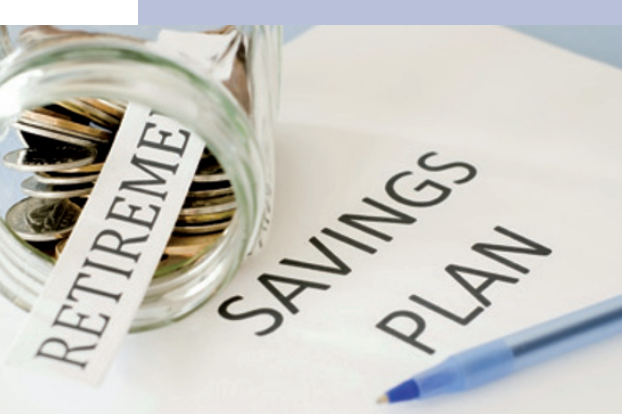

बiStock/Thinkstock

\section{SAVING LIVES THROUGH MOUTH CANCER ACTION MONTH}

With on-going support from the Association of Dental Groups (ADG), the British Dental Health Foundation's charity campaign Mouth Cancer Action Month has continued in its mission to raise awareness of mouth cancer and make a difference by saving thousands of lives through early detection and prevention.

Sponsored by ADG, the campaign attempts to get more mouth cancers diagnosed at an early stage by increasing education of the risk factors, signs and symptoms.

It also encourages members of the public to undergo regular dental visits and asks them to discuss mouth cancer with their dental professional. with a big enough pot for your desired retirement? Will the new terms mean you have to work longer than hoped?

The new rules regarding defined contribution pension plans could give added flexibility on the age you retire and additional income to support you and your family when you finish work.

Take advice from a specialist firm who dedicate their time to improving the financial affairs of dental professionals.

Dental \&t Medical Financial Services' key aim is to build and protect your wealth by offering a range of professional financial services including mortgages, commercial loans, savings and investments, wealth and income protection, and taxation and trusts.

Visit www.dentalandmedical. com or call 01403780770 for more information.

\section{THE IMPLANT RESTORATIVE COURSE}

Learn how to diagnose, plan, treat and restore implant cases with the experts from Ten Dental.

World-class mentors - Dr Martin Wanendeya and Dr Nik Sisodia - offer dentists the chance to expand the treatment options available to patients with a comprehensive, affordable and detailed course.

Through a combination of lectures, demonstrations and hands-on components, the four in-depth modules will take you right through getting started with dental implant restorations to managing more complex cases.

Become fully comfortable and competent restoring implants in your practice and gain the practical and theoretical knowledge to confidently restore implants yourself. On completion of the programme, you will also receive a complimentary Mini Prosthetics Kit to ensure implants are restored accurately.

Look after your patient's smile - book your place on The Implant Restoration Course today and see how you can benefit from improving clinical outcomes, strengthening patient relationships and the associated financial gains of restoring implants yourself.

For more information about Ten Dental and The Implant Restoration Course visit www.implantrestoration.com or call 02076227610.

\section{SUPPORT THE BDA BENEVOLENT FUND}

Committed to helping dentists in need and their families, the BDA Benevolent Fund provides vital one-off and regular loans to those in severe financial difficulty.

Regardless of age, background or beliefs, the Fund cares for all people, as long as they are, or have been, on the UK dental register.

Accidents, long-term illness and serious stress can have devastating economic consequences for anyone. The Fund supports dentists and their dependents to help them get back on track, helping to buy food and clothes, pay outstanding bills, household expenses, replace household items or go towards nursing home fees and respite care.

The Benevolent Fund relies entirely on voluntary donations to fund its vital work. Joining in with one of the charity's events, or setting up your own fundraiser can provide much needed support to dentists in need.

For more information contact administrator@dentists help.org or visit www.bdabenevolentfund.org.uk.

\section{DIGITAL IMAGING SOLUTIONS}

MyRay understands how important it is to get the most out of appointments. Its range of equipment makes it easy to prepare your patient quickly to achieve a perfect scan in seconds.

Try the Hyperion X9 with its innovative positioning system for the ultimate in comfort. With seven support points for constant stability, both you and your patient will be relaxed and you can share the results immediately on an iPad. It also enables both 2D and 3D imaging, with multiple configurations, for true full arch capability.
You can also learn more about how the Hyperion X9 works in all its functional modes with the new App, available from App Store.

To find your Local MyRay dealer call MyRay in the UK on 0870752 1121 or visit www.my-ray.co.uk. 